\title{
The Bethesda System for Reporting Cervical Cytology: A Historical Perspective
}

\author{
Ritu Nayar ${ }^{\mathrm{a}}$ David C. Wilbur ${ }^{\mathrm{b}}$ \\ a Department of Pathology, Northwestern University Feinberg School of Medicine and Northwestern Medicine, \\ Chicago, IL, and b Department of Pathology, Massachusetts General Hospital and Harvard Medical School, \\ Boston, MA, USA
}

\section{Keywords}

The Bethesda System · Reporting terminology · Pap test ·

Cervical cytology

\begin{abstract}
The aims of The Bethesda System (TBS) were to provide effective communication from the laboratory to the clinical provider; facilitate cytologic-histologic correlation; facilitate research into the epidemiology, biology, and pathology of cervical disease; and provide reproducible and reliable data for national and international statistical analysis comparisons. Dr. Diane Solomon and colleagues' contribution to cervical cancer screening, diagnosis, and management began with the inception and dissemination of TBS for reporting cervical cytology in 1988, as detailed in the accompanying article [Solomon et al.: Acta Cytol 1989;33:567-574]. The significance of TBS for the further development and implementation of standardized terminology in pathology, and the research/management of cervical cancer have continued to evolve over the past three decades. TBS has always been a multidisciplinary effort and acknowledgement needs to be given to several stakeholders who, over the years, have contributed to its success. It has been our privilege and honor to
\end{abstract}

have carried on the legacy of this seminal work, even as molecular methods are being closely integrated into cervical cancer screening, triage, and prevention.

(C) 2017 S. Karger AG, Basel

The Bethesda System (TBS) was the direct result of a series of articles published in 1987 in The Wall Street Journal by investigative reporter Walt Bogdanich, about lax practices and inaccuracies in medical laboratories. In spite of the well-accepted contribution of the Papanicolaou (Pap) test in reducing the incidence of cervical cancer, much of this breaking news focused on so called "Pap mills" in which cervical cytology specimens were being processed under less than optimal conditions. Public outcry and legislative action ensued. In response to the public's concerns about the quality of laboratory testing, particularly in physician's office laboratories and concerning Pap test interpretation, the US Congress passed the Clinical Laboratory Improvement Amendments (CLIA) in 1988. The CLIA detailed a number of quality assurance practices that laboratories must comply with, based on the type and complexity of testing they perform.

\section{KARGER}

(c) 2017 S. Karger AG, Basel

E-Mail karger@karger.com

www.karger.com/acy
Correspondence to: Dr. Ritu Nayar

Northwestern Memorial Hospital

Cytopathology Galter 7-132B, 251 East Huron Street,

Chicago, IL 60611 (USA)

E-Mail r-nayar@northwestern.edu 
Prior to TBS, US laboratories used a variety of nonreproducible terms for reporting cervical cytology including Pap test class numbers (which were completely nondescriptive) amongst other terminologies, e.g., 3-tier dysplasia (mild/moderate/severe, or carcinoma in situ) and cervical intraepithelial neoplasia (CIN). Much was made of the clinically and biologically irrelevant morphologic distinctions between human papillomavirus (HPV) cytopathic effects and low-grade dysplasia as well as the nonreproducible distinction between the grades of precancer, and these differences were often used as a clinical threshold for significant interventions. To address these issues, the National Cancer Institute (NCI) convened a workshop, under the leadership of Drs. Diane Solomon and Robert Kurman, with the aim of developing a system for reporting Pap tests that would communicate the cytology findings to clinicians in a clear and relevant fashion. A group of individuals, with expertise in gynecologic cytopathology, histopathology, and patient management, met in Bethesda, MD, USA, in December 1988, and formulated the first version of TBS [1]. This lexicon for practice was founded on 3 basic principles that continue to hold true today -3 decades and 3 updates later! Terminology must be (1) clinically relevant, (2) reasonably reproducible and flexible, and (3) reflect the most current understanding of cervical neoplasia.

TBS 1988 created a standardized framework for cervical cytology reports that included an evaluation of specimen adequacy, an optional general categorization, and a descriptive diagnosis. The inclusion of recommendations for adequacy limitations or elaborations on morphologic findings to guide management, as appropriate, was suggested. The introduction of adequacy has been considered by many to be the most important quality assurance component of TBS. The general categorization, although optional, clearly separated "normal" from "abnormal" reports and is aimed at assisting clinical providers in triaging reports for subsequent patient management. The descriptive diagnosis, on the other hand, is designed to be the essential interpretive component of the report that details the morphologic findings, i.e., infection, reactive/ reparative changes, and/or epithelial cell abnormalities, both squamous and glandular. For squamous lesions, TBS introduced a new 2-tier terminology for reporting HPV-associated squamous intraepithelial lesions (SIL): low-grade (LSIL) and high-grade (HSIL). It also allowed for a period of transition during which previously used grades of CIN, degrees of dysplasia, and the presence of HPV cytopathic changes could be appended. The new 2-tier terminology was expected to improve interobserv- er reproducibility over that seen with 3-tier systems. A major component of TBS 1988 was a clarification of the misunderstood term "atypia." As an equivocal finding, atypia had been overused and applied in a highly inconsistent manner, leading to considerable confusion about its appropriate management. In TBS, atypia was specifically defined to include only cases in which the cytologic findings were of "undetermined significance"; the term was not to be used for cases in which inflammatory, reactive, preneoplastic, or neoplastic changes were clearly present. This definition was also applied to cases of glandular epithelial abnormality. This gave rise to the nowfamiliar terms "atypical squamous cells of undetermined significance" (ASCUS) and "atypical glandular cells of undetermined significance" (AGUS).

Within a few years of its introduction, TBS gained widespread acceptance in clinical practice in the USA and, thereafter, internationally. Encouraged by the early benefits of this new standardized terminology, the NCI organized a follow-up workshop in Bethesda, $\mathrm{MD}$, in April 1991 to critically evaluate TBS and consider areas for improvement. The 1991 Workshop was attended by 182 invited experts in cytopathology and gynecology, and approximately 65 presentations were made by various laboratories to share experiences regarding the use of TBS in clinical practice. The discussions resulted in the refinement of the report format and terminology, and the development of precise criteria for the evaluation of adequacy and specific diagnostic terms. A discussion about the management of abnormalities detected by cervical cytology acknowledged the need to have clinical trial data to help in development, so interim management guidelines were published in 1991 which would be finalized after further data was gathered. The updates were presented to the cytopathology community in the form of the first Bethesda Atlas "blue book" in 1994 [2].

Of all the changes introduced by TBS, the concept of ASCUS proved to be by far the most controversial for clinicians and pathologists alike. It highlighted the intrinsic limitations of morphologic interpretation, and led to significant variability in management and outcomes which caused frustration amongst clinical providers. With increasing implementation of TBS terminology in the early 1990s, it became clear that the vast majority of abnormal cervical cytology results fell into the equivocal categories of ASCUS or LSIL. In light of the increasing clarity of HPV biology, the large volume of women with ASCUS/ LSIL cytology, which had the potential to overburden the available colposcopy resources, and the recent availability of HPV testing for potential triage, the NCI conceived the 
ASCUS-LSIL Triage Study (ALTS) to determine how best to manage women with these equivocal results. The ALTS was designed as a randomized multicenter trial to compare the 3 management strategies available: immediate colposcopy, HPV triage, and conservative follow-up. Women were recruited between 1996 and 1998, with the aim of establishing how best to avoid overreferral and overtreatment for the majority of women with clinically insignificant changes, while providing a safety net for the small percentage of women with underdiagnosed highgrade lesions [3].

The ALTS was a pivotal trial that not only achieved its main goal, but greatly informed our understanding of cervical cancer biology, which, in turn, significantly impacted clinical practice patterns. The study results established molecular testing for high-risk HPV as the most cost-effective approach to clarify equivocal cytologic findings. Follow-up data showed that the risk of CIN2+ for high-risk HPV-positive ASCUS is the same as for LSIL and should therefore be managed as such, while HPVnegative ASCUS is relatively safe and does not require immediate colposcopy. The implementation of reflex HPV testing for ASCUS decreased colposcopy referrals by up to $50 \%$. From the ALTS, we were also able to demonstrate that in screening and diagnostic workup for cervical cancer, there is no gold standard, and, indeed, cytology, colposcopy, and histology are all subject to variable performance. Interobserver "non-reproducibility" of pathologic interpretations was shown to be comparable, for both histopathology and cytology and, at best, average [4]. Similarly, intake colposcopy in the ALTS had a sensitivity of $53 \%$ for subsequent CIN2+ and an overall sensitivity of $70 \%$ for CIN3+. Thus colposcopy, like cytology and histology, was found to be subjective and detected only about $2 / 3$ rd of CIN $3+$ [5].

From the onset, TBS was expected to continue to evolve with time in response to advances in the understanding of cervical neoplasia and the changing needs of the cytopathology and clinical communities. In 2001, the third TBS workshop was held to consider updates based on practice changes, and advances in science and technology. In order to broaden participation both within the USA and internationally, draft recommendations were posted on an Internet bulletin board, and over 2,000 comments were considered prior to the multidisciplinary workshop. TBS 2001 was attended by over 400 people from 24 countries and 44 professional societies. A number of significant updates occurred in 2001 that can be summarized as follows:
1. General. (a) The terms "interpretation" or "result" were recommended in lieu of "diagnosis" in the header of the cervical cytology report, since it is a screening test, which serves as a medical consultation by providing an interpretation that contributes to a diagnosis when integrated with patient history, clinical findings, and the results of other laboratory tests such as cervical biopsy. (b) Acknowledging that TBS was developed primarily for cervical cytology, it was decided that specimens from other sites in the lower anogenital tract, such as the vagina and anus, could also be reported using this terminology.

2. Terminology. (a) Squamous lesions: consideration was given to the possibility of eliminating the ASCUS interpretive category, but this was not done due the unacceptable loss of sensitivity and positive predictive value for HSIL that it would portend. Instead, it was modified to ASC, with a narrower definition and a simple dichotomous system of qualifiers, i.e., ASC-US and ASC-H, which also mirrored HPV biology. (b) Glandular lesions: while TBS emphasizes that cervical cytology is not a screening test for adenocarcinoma, improvements in sampling devices and experience with cytomorphologic recognition of glandular abnormalities led to the addition of "endocervical adenocarcinoma in situ" (AIS) as a distinct interpretative category, and the "atypical glandular cells" (AGC) category was refined to specify the glandular cell type and better reflect concern for neoplasia so as to provide more guidance for management.

The NCI and the American Society of Cytopathology collaborated, under the leadership of Drs. Diane Solomon and Ritu Nayar, to facilitate the dissemination of the TBS 2001 update. Three educational methods were utilized:

1. The 2nd edition of the Bethesda print atlas addressed the reporting changes, and was significantly expanded with a new chapter-based format and the addition of background, detailed interpretive criteria, ample illustrations, explanatory notes, management guidelines, and sample reports. New technologies such as liquidbased cytology, automation, computer-assisted imaging, and HPV testing were also included [6].

2. A companion Bethesda Web atlas was established in conjunction with the print atlas. It had more images than the print atlas, and the ability to perform searches by morphology, preparation type, etc., as well as a self-test [7].

3. The Web-based Bethesda Interobserver Reproducibility Study (BIRST), using a subset of images from the 2nd edition of the Bethesda atlas prior to its publica- 
tion, was undertaken to gain additional insight into consensus among cytologists with varied training and experience, and to identify specific cytomorphologic features and reporting categories that represented sources of poor agreement. The results confirmed that the a priori difficulty of the image was a more important determinant of agreement than the characteristics of the participant [8].

Immediately following the 2001 Bethesda Workshop, the American Society for Colposcopy and Cervical Pathology (ASCCP) held a multidisciplinary consensus conference to develop management strategies for cytologic abnormalities conforming to TBS categories [9]. The results of ALTS and other clinical research formed the basis for guideline development. This was a historic event where, for the first time, reporting terminology correlated with both biology and clinical management. These evidence-based management guidelines were updated in 2006 and 2012, based on additional data from subsequent trials and clinical experience in the USA, and they are now widely accepted as the standard of care $[10,11]$.

Between 2001 and 2014, with the approval and implementation of prophylactic HPV vaccination and primary HPV screening as an alternative option for the secondary prevention of cervical cancer, the role and performance characteristics of cervical cytology were gradually but surely changing in various parts of the world. In vaccinated populations, the removal of the HPV 16 and HPV18 genotypes will lead to a subsequent decreased prevalence of high-grade lesions. In the primary HPV screening algorithm with reflex cytology only for women who are HPV-positive but do not have HPV16/18, the Pap test will take on more of a "diagnostic" role. Thus, it will be imperative to maintain the sensitivity of cytology for it to be utilized in this application. In addition, another decade of experience with liquid-based cytology, and other technologic advances such as immunocytochemistry and molecular process was gained, leading to the need for another TBS update.

The 2014 TBS revision, which occurred under the leadership of Drs. Ritu Nayar and David C. Wilbur, anticipated minimal changes in terminology, and it was largely undertaken to provide cytologists and clinicians with an extensive educational resource to include basic concepts, more morphologic clues, pitfalls, and histologic correlations, and also to update management guidelines. An additional non-morphologic chapter was also added, detailing the current conceptual approach to overall risk assessment-based management. The 3rd edition of the Bethesda atlas was significantly larger and published in print and electronic formats in 2015 [12, 13]. It was also accompanied by a companion Bethesda 2014 website which contains images from the BIRST-2 project conducted in conjunction with this update [14, 15]. It was gratifying to see that the prior educational efforts and experience resulted in a marked improvement in almost all interpretative categories when compared to BIRST-1, although the performance of glandular lesions is still less reproducible than that of squamous lesions and the image difficulty remains the main determinant of agreement.

One of the most significant contributions of the process is that TBS has served as a model for the development of other standardized reporting systems in cytopathology and histopathology. The Bethesda System for Thyroid Cytopathology, the Paris System for Urinary Cytopathology, the Milan System for Salivary Gland Cytology, and the Papanicolaou Society of Cytopathology Guidelines for Pancreaticobiliary Cytology have all followed educational efforts similar to TBS [16-19]. Extension of the 2-tiered terminology of LSIL and HSIL is now recognized by the World Health Organization, and by the ASCCP, and College of American Pathologists for reporting histopathology of specimens from the lower anogenital tract $[20,21]$.

The success of TBS rests on sound principles that were key to adopting and implementing it as an international standardized reporting terminology for cervical cytology. TBS (a) is based on evidence, inclusion and consensus; (b) correlates with biology and management; (c) is concise and practical; (d) is flexible enough to be adopted by different geographic/laboratory settings; (e) allows for change with the increase of knowledge and experience; and (f) incorporates multiple educational endeavors (atlases, websites, and BIRST). Editors and authors of the cervical cytology Bethesda atlases have always been committed to making the educational materials affordable, and therefore widely accessible, by foregoing all honoraria or royalties.

In summary, TBS serves as a landmark and exemplary contribution to standardized reporting. The following excerpts are an appropriate end to this discourse:

It is paradoxical that instead of TBS responding to new developments and changes, it has actually led the way in many areas. TBS played a vital role in initiating research in the biology of cervical cancer, in exploring new approaches and strategies in patient management and in incorporating new technologies into cervical cancer screening. (Foreword by Robert Kurman in the 2nd edition of The Cervical Cytology Bethesda Atlas, 2004 [6].) 
I never imagined that a small meeting on the campus of the National Institutes of Health in Bethesda, Maryland, one snowy weekend in December 1988 would begin a process that has changed the practice of cervical cytology - in both the laboratory and the clinician's office - around the world. (Preface by Diane Solomon to the 3rd edition of The Cervical Cytology Bethesda Atlas, 2015 [13].)

\section{Disclosure Statement}

The authors have no conflicts of interest to declare. 


\section{The 1988 Bethesda}

System for Reporting

Cervical/Vaginal

Cytologic Diagnoses

Developed and Approved at the National Cancer Institute

Workshop, Bethesda, Maryland, U.S.A., December 12-13, 1988
Address reprint requests to: Diane Solomon, M.D., M.I.A.C., Cytopathology Section, Building 10, Room 2A33, National Cancer Institute, National Institutes of Health, 900 Rockville Pike, Bethesda, MD 20892.

\section{Background}

The death rate from cervical cancer has dropped significantly in the last 40 years, a decrease that has been attributed largely to the widespread use of the "Pap test." Recent criticism of cervical/vaginal cytology, however, has focused the attention of the medical profession, governmental agencies and legislative bodies on the need for strengthening quality assurance measures in cytopathology. One critical aspect of quality assurance in cervical/vaginal cytology is communication of the cytopathologic findings to the referring physician in unambiguous diagnostic terms that have clinical relevance. Terminology currently used is varied and in some instances ambiguous, resulting in confusion about the clinical implications of the report.

As a result of this ambiguous terminology, the Division of Cancer Prevention and Control, National Cancer Institute (NCI), convened a Workshop of expert consultants, distinguished cytopathologists and representatives from national medical and other organizations (Appendix I) to review existing terminology and to recommend effective methods of reporting. The Workshop met at the National Institutes of Health (NIH) campus in Bethesda, Maryland, on December 12-13, 1988.

Robert V. P. Hutter, M.D., served as Chairman and Donald Earl Henson, M.D., as Executive Secretary of the Workshop. Diane Solomon, M.D., served as Chairman of the Terminology Group that prepared a draft outline for discussion at the Workshop.

\section{Recommendations}

The participants unanimously approved the following:

(A) The cytopathology report is a medical consultation.

(B) The Papanicolaou classification for reporting consultations is not acceptable in the modern practice of diagnostic cytopathology.

(C) The Bethesda System should serve as a guideline for cytopathology reports of cervical/vaginal specimens. 
(A) The Cytology Report Is a Medical Consultation The participants unanimously affirmed that the cytopathology report is a medical consultation.

(1) The cytopathologist has ultimate responsibility for the diagnostic evaluation and report.

(2) The referring physician has an obligation to include all pertinent clinical information in the request for cytologic evaluation so that the cytopathologist can consult effectively.

(3) The cytopathologist should determine whether the specimen is adequate for diagnostic evaluation. If unsatisfactory or less than optimal, this should be noted in the report.

(4) The diagnostic report should include a recommendation for further patient evaluation when appropriate.

(B) The Papanicolaou Classification Is Unacceptable While the Papanicolaou classification has a significant historical association with the early development of cytology, it does not reliably communicate clinically relevant information. The participants focused on four major deficiencies of the Papanicolaou classification:

(1) The Papanicolaou classification does not reflect current understanding of cervical/vaginal neoplasia.

(2) The Papanicolaou classes have no equivalent in diagnostic histopathologic terminology.

(3) The Papanicolaou classes do not provide diagnoses for noncancerous entities.

(4) As a result of numerous idiosyncratic modifications, the specific Papanicolaou classes no longer reflect diagnostic interpretations uniformly.

Accordingly, the participants unanimously concluded that the Papanicolaou classfication is not acceptable in the modern practice of diagnostic cytology.

(C) The Bethesda System for Reporting Cervical/Vaginal Cytologic Diagnoses

The participants recognized that a uniform reporting system for cervical/vaginal cytology will:

- provide for effective communication among cytopathologists and referring physicians;

- facilitate cytologic-histopathologic correlation;

- facilitate research into the epidemiology, biology and pathology of cervical disease; and

- provide reliable data for national and international statistical analysis comparisons.

The participants considered the criteria needed for a uniform terminology and reporting system. They agreed that the primary purpose of diagnostic terminology is to communicate to the referring physician information that can be used for patient management. The terminology should reflect current understanding of the pathogenesis of cervical/vaginal disease, and provide a framework that is flexible enough to accommodate advances in virology, molecular biology and pathology. Finally, to facilitate utilization of The Bethesda System, the participants agreed to minimize the introduction of new diagnostic terms.

Low-Grade and High-Grade Squamous Intraepithelial Lesions. The lack of consistency in subclassifying squamous epithelial dysplasia, cervical, intraepithelial neoplasia (CIN) and other epithelial abnormalities of the cervix that form a morphologic continuum of precursors to squamous cell carcinoma was considered in detail. Years of experience have demonstrated the lack of reproducibility in assigning cervical lesions to categories of mild, moderate and severe dysplasia, carcinoma in situ (CIS) or CIN 1, CIN 2 or CIN 3. As a result, the participants introduced only two terms: low-grade squamous intraepithelial lesion and high-grade squamous intraepithelial lesion.

These two new terms encompass the spectrum of terms currently used to delineate the squamous cell precursors to invasive squamous carcinoma, including the grades of CIN, the degrees of dysplasia and CIS. "Cellular changes associated with human papillomavirus," (without features of "dysplasia" or " $\mathrm{CIN}^{\prime \prime}$ ) may be used as a separate diagnostic statement, although the participants recommend that it be included under the designation of low-grade squamous intraepithelial lesion. Some cytopathologists, especially during the phasing-in process, may wish to use their previous terminology in conjunction with the new terms, as in the following examples: "lowgrade squamous intraepithelial lesion: cellular changes associated with human papillomavirus (HPV)," or "low-grade squamous intraepithelial lesion: mild dysplasia and cellular changes associated with human papillomavirus (HPV)," or "high-grade squamous intraepithelial lesion: cervical intraepithelial neoplasia (CIN 3)."

Atypia. The Bethesda System limits use of the term atypical cells to those cases in which the cytologic findings are of undetermined significance. "Atypia" should not be used as a diagnosis for otherwise defined inflammatory, preneoplastic or neoplastic cellular changes. In order to assist the referring physician, a report in which cells are described as "atypical" should include a recommendation for further 
evaluation that may help to determine the significance of the atypical cells. For example, if the descriptive diagnosis was "atypical squamous cells of undetermined significance associated with atrophy," the recommendation for further action might be "suggest administration of estrogen followed by repeat smear."

Formation of the National Cancer Institute Ad Hoc Working Group

The final recommendation was that an ad hoc Working Group be formed under the auspices of the NCI to assess the use of The Bethesda System. Members of this Working Group would serve primarily as a liaison with their respective professional organizations. They would also have the responsibility for tracking educational activities, preparing articles for publication and eliciting the cooperation of physicians and cytotechnologists in using The Bethesda System. The Bethesda System is a flexible guideline and can be modified as appropriate to meet the needs of cytopathologists, their referring physicians and patients.

\section{Format of the Report}

It is recommended that a cervical/vaginal cytopathology report address each of the following elements:

(A) a STATEMENT ON THE ADEQUACY OF THE SPECIMEN for diagnostic evaluation;

(B) a GENERAL CATEGORIZATION of the diagnosis (as "within normal limits" or "other"); and

(C) the DESCRIPTIVE DIAGNOSIS.

The format and terminology recommended for each of these three elements are presented below.

\section{STATEMENT ON SPECIMEN ADEQUACY}

- Satisfactory for Interpretation

- Less Than Optimal

- Unsatisfactory

Explanation for "Less Than Optimal/

Unsatisfactory Samples":

- Scant cellularity

- Poor fixation or preservation

- Presence of foreign material (e.g., lubricant)

- Partially or completely obscuring inflammation

- Partially or completely obscuring blood

- Excessive cytolysis or autolysis

- No endocervical component in a premenopausal woman who has a cervix

- Not representative of the anatomic site
- Other:

\section{GENERAL CATEGORIZATION}

- Within Normal Limits

- Other:

- See descriptive diagnosis

- Further action recommended

\section{DESCRIPTIVE DIAGNOSES}

\section{- INFECTION}

- Fungal

- Fungal organisms morphologically consistent with Candida sp.

- Other:

- Bacterial

- Microorganisms morphologically consistent with Gardnerella sp.

- Microorganisms morphologically consistent with Actinomyces sp.

- Cellular changes suggestive of Chlamydia $s p$. infection, subject to confirmatory studies

- Other:

- Protozoan

- Trichomonas vaginalis

- Other:

- Viral

- Cellular changes associated with cytomegalovirus

- Cellular changes associated with herpes simplex virus

- Other:

[Note: For human papillomavirus (HPV), refer to Epithelial Cell Abnormalities, Squamous Cell]

- Other:

\section{- REACTIVE AND REPARATIVE CHANGES}

- Inflammation

- Associated cellular changes

- Follicular cervicitis

- Miscellaneous (as related to patient history)

- Effects of therapy

- Ionizing radiation

- Chemotherapy

- Effects of mechanical devices (e.g., intrauterine contraceptive device)

- Effects of non-steroidal estrogen exposure (e.g., diethylstilbestrol)

- Other: 


\section{- ePITHELIAl CELl ABNORMAlities}

Squamous Cell

- Atypical squamous cells of undetermined significance (recommended follow-up and/or type of further investigation):

- Squamous intraepithelial lesion (SIL) [comment on presence of cellular changes associated with HPV if applicable]

- Low-grade squamous intraepithelial lesion, encompassing:

(1) Cellular changes associated with HPV

(2) Mild (slight) dysplasia/cervical intraepithelial neoplasia grade 1 (CIN 1)

- High-grade squamous intraepithelial lesion, encompassing:

(1) Moderate dysplasia/CIN 2

(2) Severe dysplasia/CIN 3

(3) Carcinoma in situ/CIN 3

- Squamous cell carcinoma

Glandular cells

- Presence of endometrial cells in one of the following circumstances:

- Out-of-phase in a menstruating woman

- In a postmenopausal woman

- No menstrual history available

- Atypical glandular cells of undetermined significance (recommended follow-up and/or type of further investigation)

- Endometrial

- Endocervical

- Not otherwise specified

- Adenocarcinoma

- Specify probable site of origin: endocervical endometrial, extrauterine

- Not otherwise specified

- Other epithelial malignant neoplasm:

- NON-EPITHELIAL MALIGNANT NEOPLASM

(SPECIFY):

HORMONAL EVALUATION (APPLIES TO

VAGINAL SMEARS ONLY

- Hormonal pattern compatible with age and history

- Hormonal pattern incompatible with age and history

Specify:

- Hormonal evaluation not possible

- Cervical specimen
- Inflammation

- Insufficient patient history

- OTHER:

Explanatory Notes

The following comments are provided as explanatory notes to The Bethesda System for reporting cervical/ vaginal cytologic diagnoses.

\section{Statement on Specimen Adequacy}

In The Bethesda System, three positive responses are listed under the heading STATEMENT ON SPECIMEN ADEQUACY:

(A) "Satisfactory" indicates the specimen is an adequate sample that can be interpreted without qualification.

(B) "Less Than Optimal" indicates the specimen may provide useful diagnostic information but is less than optimal (for example, because of partially obscuring inflammation).

(C) "Unsatisfactory" indicates the specimen is not acceptable for diagnostic evaluation and repeat sampling may be warranted.

Use of the category "Less Than Optimal" is optional.

An EXPLANATION should be provided for any specimen designated either "Less Than Optimal" or "Unsatisfactory." The Bethesda System includes the entry "No endocervical component in a premenopausal woman who has a uterine cervix" to indicate that none of the following elements is present: (a) endocervical cells, (b) endocervical mucus or (c) squamous metaplastic cells.

The cytopathologist should recommend a repeat smear when reporting an "Unsatisfactory" specimen. For "Less Than Optimal" specimens, the cytopathologist may choose to recommend a repeat smear or other follow-up.

\section{General Categorization}

The second element of the report format sorts reports (except those labeled "Unsatisfactory") to either: "Within Normal Limits" or "Other." If "Other" is selected, the report may include an additional notation if further action is recommended. The "General Categorization" is not a substitute for specific descriptive diagnoses, which can be included elsewhere in the report. Rather, it is to assist the referring physician and support personnel to sort cases for review and/or further action. 


\section{Descriptive Diagnosis}

The final element of the recommended report format of The Bethesda System is the descriptive diagnosis, which is largely self-explanatory as outlined. With the exception of two new terms, the others are in geineral use. However, a few points are clarified below.

\section{(A) Infection}

The Bethesda System lists those infectious agents associated with cervical/vaginal disease, the presence of which can be suggested by cytologic examination. However, definitive diagnosis of some of these agents may require confirmatory studies. The qualifying phrases accompanying the identification of certain pathogens such as "fungal organisms morphologically consistent with Candida sp." reflect the level of diagnostic certainty by routine light microscopy alone. These phrases can be modified to suit the individual cytopathologist.

\section{(B) Epithelial Cell Abnormalities}

1. Atypia. The Bethesda System limits use of the term atypical cells to those cases in which the cytologic findings are of undetermined significance. "Atypia" should not be used as a diagnosis for otherwise defined inflammatory, preneoplastic or neoplastic cellular changes.

To assist the referring physician, a report in which cells are described as "atypical" should include a recommendation for further evaluation that may help to determine the significance of the atypical cells.

2. Squamous Intraepithelial Lesion (SIL). The only new diagnostic terms in The Bethesda System are low-grade squamous intraepithelial lesion and highgrade squamous intraepithelial lesion. They encompass the spectrum of terms currently used for squamous cell precursors to invasive squamous cell carcinoma, including the grades of $\mathrm{CIN}$, the degrees of dysplasia and CIS. "Grade," as used with SIL, does not connote invasive carcinoma.

While low-grade SIL and high-grade SIL are preferred, use of these new terms does not preclude the addition of the degree of "dysplasia" or grade of "CIN" for cytopathologists who wish to retain these designations: for example, "low-grade squamous intraepithelial lesion: cellular changes associated with human papillomavirus (HPV)," "low-grade squamous intraepithelial lesion: mild dysplasia and cellular changes associated with human papillomavirus
$(H P V)$ " or "high-grade squamous intraepithelial lesion: cervical intraepithelial neoplasia, grade 3 (CIN 3)."

The statement cellular changes associated with human papillomavirus (HPV) is added to the report of either low-grade SIL or high-grade SIL when appropriate. Cellular changes associated with HPV (without features of "dysplasia" or "CIN") may be used as a separate diagnostic phrase, although it is recommended that it be included under the designation low-grade SIL. Terms such as koilocytic atypia, keratinizing atypia and dyskaryosis are not included in The Bethesda System lexicon.

\section{Appendix}

List of Workshop Participants

Roger L. Aamodt, Ph.D.

Program Director for Pathology/Cytology

Cancer Diagnosis Branch

National Cancer Institute

Bethesda, Maryland 20892

Kara Anderson, R.N.C., B.A.

Planned Parenthood Federation

810 7th Avenue

New York, New York 10019

Patricia Ashton, C.T.(ASCP), C.T.(IAC)

American Society for Cytotechnology

708 Wendy Way

Durham, North Carolina 27712

Larry Bergner, M.D.

Cancer Control Applications Branch

Division of Cancer Prevention and Control

National Cancer Institute

Bethesda, Maryland 20892

Miklos Bodo, M.D., M.I.A.C. ${ }^{\star} \dagger$

Immediate Past President,

European Federation of Cytology Societies

Division of Cancer Prevention and Control

National Cancer Institute

Bethesda, Maryland 20892

Doris N. Collins, M.D., M.I.A.C

Director, Wadsworth Center for Labs and Research New York State Department of Health

Empire State Plaza

Albany, New York 12201 
Veronica Conley, Ph.D.

Early Detection Branch

Division of Cancer Prevention and Control

National Cancer Institute

Bethesda, Maryland 20892

Inajo S. Cox, C.T. (ASCP)

Supervisor Cytology

National Health Laboratories

1007 Electric Avenue

Vienna, Virginia 22180

Yener S. Erozan, M.D., F.I.A.C. ${ }^{*}$

Immediate Past President,

American Society of Cytology

Department of Pathology

Johns Hopkins University Hospital

600 North Wolfe Street

Baltimore, Maryland 21205

Gilbert H. Friedell, M.D.

Director, Lucille Parker Markay Cancer Center 800 Rose Street

Lexington, Kentucky 40536-0093

John K. Frost, M.D., F.I.A.C.

Past President, American Society of Cytology Professor of Pathology

Johns Hopkins University Hospital

600 North Wolfe Street

Baltimore, Maryland 21205

Claudia Gaffey, M.D.

10105 Frederick Avenue

Kensington, Maryland 20895

Monica Gallivan, M.D.

American Medical Labs.

P.O. Box 188

Fairfax, Virginia 22030

Lorraine D. Gawronski, C.T. (ASCP)

American Society for Cytotechnology

2406 Sugarberry Court

Reston, Virginia 22091

Shirley E. Greening, C.T.(ASCP), C.F.I.A.C. $\dagger$

American Society for Cytotechnology

Department of Laboratory Science

Thomas Jefferson University

130 South 9th Street

Philadelphia, Pennsylvania 19107
Prabodh K. Gupta, M.D., F.I.A.C.

Director, Department of Cytology

Hospital of the University of Pennsylvania 3400 Spruce Street

Philadelphia, Pennsylvania 19102

Vivien Hanson, M.D.

4032 Burton Place West

Seattle, Washington 98199

Donald Earl Henson, M.D. *

Early Detection Branch

Division of Cancer Prevention and Control

National Cancer Institute

Bethesda, Maryland 20892

Robert V. P. Hutter, M.D.*

Chairman, College of American

Pathologists Cancer Committee

Chairman, Department of Pathology

St. Barnabas Medical Center

98 Old Short Hills Road

Livingston, New Jersey 07039

Stanley L. Inhorn, M.D., F.I.A.C.

Past President, American Society of Cytology

Professor of Pathology and Director,

State Laboratory of Hygiene

University of Wisconsin Center for Health Sciences 465 Henry Mall

Madison, Wisconsin 53706

Gitie Jaffe, M.D.

Cytopathology Section

Laboratory of Pathology

National Cancer Institute

Bethesda, Maryland 20892

William J. Jaffurs, M.D.

Pathologist and Director

Cytology Services of Maryland

P.O. Box 1126

Silver Spring, Maryland 20910

William W. Johnston, M.D., F.I.A.C.

Past President, American Society of Cytology

Professor of Pathology and Director,

Division of Cytopathology

Duke University Medical Center

Durham, North Carolina 27710 
Harold A. Kaminetzky, M.D.

Director of Practice Activities

American College of Obstetricians and Gynecologists 409 12th Street, S.W.

Washington, D.C. 20024

Tilde S. Kline, M.D., M.I.A.C.

Chief, Division of Cytology

Department of Pathology

Lankenau Hospital

Lancaster \& City Lane Avenues

Philadelphia, Pennsylvania 19151

Beverly Balfour Kraemer, M.D., M.I.A.C. $†$

Chairperson, College of

American Pathologists Cytology Committee

Director of Cytopathology

St. John's Mercy Medical Center

615 South Ballas Road

St. Louis, Missouri 63141

Robert J. Kurman, M.D.†

Professor of Pathology and

Professor of Obstetrics and Gynecology

Johns Hopkins University Hospital

600 North Wolfe Street

Baltimore, Maryland 21205

Ronald D. Luff, M.D.* $\dagger$

Director of Cytopathology

Department of Pathology

Sacred Heart Hospital

Allentown, Pennsylvania 18102

George D. Malkasian, M.D.

President Elect, American

College of Obstetricians and Gynecologists

Chairman of Obstetrics and Medical Gynecology

Mayo Clinic

200 First Street, S.W.

Rochester, Minnesota 55905

Richard C. Marsella, M.D., Ph.D.*

Registrar, American Registry of Cytology

Department of Cellular Pathology

Armed Forces Institute of Pathology

Washington, D.C. 20306

Maria Mason, M.D.

5301 Strathmore Avenue

Kensington, Maryland 20892
Lynda McGoldrick, R.N., O.C.N.

1911 Franklin Avenue

McLean, Virginia 22101

William Miller, M.D.

Smith Kline Bioscience Laboratories

506 East State Parkway

Schaumburg, Illinois 60173

Robin Miller-Catchpole, M.D.

Physician Consultant

American Medical Association

535 North Dearborn Street

Chicago, Illinois 60610

Bernard Naylor, M.D., F.I.A.C.

Secretary-Treasurer, American Society of Cytology

Professor of Pathology

University of Michigan Hospital

1500 East Medical Center Drive

Ann Arbor, Michigan 48109-0054

Robert C. Park, M.D.

President, American

College of Obstetricians and Gynecologists

Chairman,

Department of Obstetrics and Gynecology

Walter Reed Army Medical Center

Washington, D.C. 20307

James E. Parker, M.D., M.I.A.C.

Past President, American Society of Cytology

Professor of Pathology

University of Louisville School of Medicine

Louisville, Kentucky 40292

A. Elizabeth Plott, C.T.(ASCP), C.M.I.A.C.

Research Cytotechnologist,

Cytopathology Laboratory

Division of Chronic Disease Control and

Community Intervention

Center for Chronic Disease Prevention and

Health Promotion

Centers for Disease Control

Atlanta, Georgia 30333

Dorothy L. Rosenthal, M.D., F.I.A.C.

Professor of Pathology and

Director, Cytology Service

University of California at Los Angeles

Medical Center

Los Angeles, California 90024 
Patricia E. Saigo, M.D., M.I.A.C. ${ }^{\star} \dagger$ President, American Society of Cytology Department of Pathology Memorial Sloan-Kettering Cancer Center 1275 York Avenue

New York, New York 10021

Shirley Shelton

American College of Obstetricians and Gynecologists 409 12th Street, S.W.

Washington, D.C. 20024

Steven G. Silverberg, M.D.

Professor and Chairman,

Department of Anatomic Pathology

George Washington University Medical Center

901 23rd Street, N.W.

Washington, D.C. 20037-2327

Charles Smart, M.D.

Chief, Early Detection Branch

Division of Cancer Prevention and Control

National Cancer Institute

Bethesda, Maryland 20892

\section{Jacquelyn Smith}

Cytopathology Section

Laboratory of Pathology

Division of Cancer Biology and Diagnosis

National Cancer Institute

Bethesda, Maryland 20892

Diane Solomon, M.D., M.I.A.C. ${ }^{\star} \dagger$

Chief, Cytopathology Section

Laboratory of Pathology

Division of Cancer Biology and Diagnosis

National Cancer Institute

Bethesda, Maryland 20892
Kelly Sorenson, M.D., M.I.A.C. $†$

Director of Cytopathology

Case Western Reserve University Hospital

Institute of Pathology, Room 224

2085 Adelbert Road

Cleveland, Ohio 44106

Gerald L. Troutman, C.T.(ASCP)

Laboratory Manager

Cytology Services of Maryland

P.O. Box 1126

Silver Spring, Maryland 20910

Sharon Wentland, C.T. (ASCP)

Pathology Department (Cytology)

Arlington Hospital

Arlington, Virginia 22205

W. Budd Wentz, M.D.

Professor of Reproductive Biology

Case Western Reserve University Hospital

Cleveland, Ohio 44106

George L. Wied, M.D., F.I.A.C. ${ }^{*} \dagger$

Past President, American Society of Cytology and International Academy of Cytology

Professor of Pathology and Blum-Riese Chair of Obstetrics and Gynecology

University of Chicago

5841 South Maryland Avenue-HM 449

Chicago, Illinois 60637-1463

John Wilson, M.D.

American Cancer Society, Inc.

3340 Peachtree Road, N.E.

Atlanta, Georgia 30036

-Denotes a member of the Editorial Group.

tDenotes a member of the Terminology Working Group.

\section{Notice to contributors to this journal}

In order to facilitate and foster the introduction of a uniform terminology in the reporting of cytologic samples from the female reproductive tract, this journal will accept manuscripts only if they comply with the standards set forth in The Bethesda System above; among other criteria, e.g., references to the Papanicolaou classes will not be acceptable in publications in this journal. However, comments on The Bethesda System and its possible future emendations are encouraged and will be transmitted to the appropriate committees and/or accepted for publication as letters to the editors.

The Editor-in-Chief 


\section{References}

1 Solomon D, et al: The 1988 Bethesda System for reporting cervical/vaginal cytologic diagnoses. Developed and approved at the $\mathrm{Na}$ tional Cancer Institute Workshop, Bethesda, Maryland, USA, December 12-13, 1988. Acta Cytol 1989;33:567-574.

2 Kurman RJ, Solomon D (eds): The Bethesda System for Reporting Cervical/Vaginal Cytologic Diagnoses. Definitions, Criteria, and Explanatory Notes for Terminology and Specimen Adequacy. New York, Springer, 1994.

3 Schiffman M, Adrianza ME: ASCUS-LSIL triage study. Design, methods and characteristics of trial participants. Acta Cytol 2000;44: 726-742.

4 Stoler MH, Schiffman M: Interobserver variability of cervical cytologic and histologic interpretations: realistic estimates from the ASCUS-LSIL triage study. JAMA 2001;285: 1500-1505.

5 Gage JC, Hanson VW, Abbey K, Dippery S, Gardner S, Kubota J, Schiffman M, Solomon D, Jeronimo J: Number of cervical biopsies and sensitivity of colposcopy. Obstet Gynecol 2006; 108:264-272.

6 Solomon D, Nayar R (eds): The Bethesda System for Reporting Cervical Cytology. Definitions, Criteria, and Explanatory Notes. New York, Springer, 2004.

7 Sherman ME, Dasgupta A, Schiffman M, Nayar R, Solomon D: The Bethesda Interobserver Reproducibility Study (BIRST): a web based assessment of the Bethesda 2001 System for classifying cervical cytology. Cancer Cytopathol 2007;111:15-25.
8 National Cancer Institute, American Society of Cytopathology: Bethesda System Website Atlas. http://nih.techriver.net/ (accessed May 9, 2017).

9 Wright TC, Cox JT, Massad LS, Twiggs LB, Wilkinson EJ: 2001 Consensus guidelines for the management of women with cervical cytological abnormalities. JAMA 2002;287: 2120-2129.

10 Wright TC Jr, Massad SL, Dunton CJ, Spitzer M, Wilkinson EJ, Solomon D: 2006 Consensus guidelines for the management of women with abnormal cervical cancer screening tests. Am J Obstet Gynecol 2007; 197:346-355.

11 Massad LS, Einstein MH, Huh WK, Katki HA, Kinney WK, Schiffman M, Solomon D, Wentzensen N, Lawson H: 2012 Updated consensus guidelines for the management of abnormal cervical cancer screening tests and cancer precursors. J Low Genit Tract Dis 2013;17(5 suppl 1):S1-S27.

12 Nayar R, Wilbur DC: The Pap test and Bethesda 2014. Cancer Cytopathol 2015:123:271281.

13 Nayar R, Wilbur DC (eds): The Bethesda System for Reporting Cervical Cytology, ed 3. Definitions, Criteria, and Explanatory Notes. New York, Springer, 2015.

14 The 2014 Bethesda Cervical Cytology Web Atlas. https://bethesda.soc.wisc.edu/ (accessed May 10, 2017).

15 Kurtycz DFI, Staats P, Chute D, Russell D, Pavelec D, Monaco SE, Friedlander MA, Wilbur DC, Nayar R: Bethesda Interobserver Reproducibility Study-2 (BIRST-2): Bethesda System 2014. J Am Soc Cytopathol 2017;6: 131-144.
16 Ali SZ, Cibas ES (eds): The Bethesda System for Reporting Thyroid Cytopathology. Definitions, Criteria, and Explanatory Notes. New York, Springer, 2010.

17 Layfield LJ, Pitman MB, DeMay RM, Shidham VB: Pancreaticobiliary tract cytology: journey toward "Bethesda" style guidelines from the Papanicolaou Society of Cytopathology. Cytojournal 2014;11:18.

18 Rosenthal DL, Wojcik EM, Kurtycz DFI (eds) The Paris System for Reporting Urinary Cytology. New York, Springer, 2016.

19 Rossi ED, Faquin WC, Baloch Z, Barkan GA, Foschini MP, Pusztaszeri M, Vielh P, Kurtycz DFI: The Milan system for reporting salivary gland cytopathology: analysis and suggestions from initial survey. Cancer Cytopathol 2017 (in press).

20 Darragh TM, Colgan TJ, Cox JT, Heller DS, Henry MR, Luff RD, McCalmont T, Nayar R, Palefsky JM, Stoler MH, Wilkinson EJ, Zaino RJ, Wilbur DC; LAST Project Work Groups: The lower anogenital squamous terminology standardization project for HPV-associated lesions: background and consensus recommendations from the College of American Pathologists and the American Society for Colposcopy and Cervical Pathology. Arch Pathol Lab Med 2012;136:1266-1297.

21 Stoler M, Bergeron C, Colgan TJ, Ferenczy AS, Herrington CS, Kim K-R: Epithelial tumours, part of tumours of the uterine cervix; in Kurman RJ, Carcangiu ML, Herrington CS, Young RH (eds): WHO Classification of Tumours of Female Reproductive Organs, chapt 7, ed 4. Lyon, IARC, 2014, pp 172-198. 